\title{
High-frequency ventilation augments the effect of inhaled nitric oxide in persistent pulmonary hypertension of the newborn
}

\author{
T. Hoehn, M. Krause, R. Hentschel
}

High-frequency ventilation augments the effect of inhaled nitric oxide in persistent pulmonary hypertension of the newborn. T. Hoehn, M. Krause, R. Hentschel. OERS Journals Ltd 1998.

ABSTRACT: Does inhaled nitric oxide (iNO) during high-frequency ventilation (HFV) lead to a more pronounced improvement in oxygenation than iNO during conventional ventilation?

We report two cases of newborn infants with profound hypoxaemia, who did not respond with an increase in arterial oxygenation following iNO therapy during conventional mechanical ventilation. The first infant was a term neonate with persistent pulmonary hypertension of the newborn (PPHN) following postnatal hypoxia, the second patient a premature infant of 29 weeks of gestation with PPHN secondary to lung hypoplasia and perinatal asphyxia. After the initial failure of iNO we switched both neonates to HFV without NO, which did not lead to a significant improvement of oxygenation in either case. Shortly after the initiation of HFV a second trial of iNO was started.

Both infants responded favourably to iNO with a marked and sustained increase in arterial oxygenation and absent right-to-left shunting via the ductus arteriosus and the foramen ovale.

We conclude that the favourable response to inhaled nitric oxide is dependent on the degree of lung expansion and is more readily achieved by the use of high-frequency ventilation than conventional ventilation.

Eur Respir J 1998; 11: 234-238.

High-frequency ventilation (HFV) is widely used for rescue treatment of hypoxaemic neonates and premature infants [1]. Although its role as a first-line mode of ventilation has not been established, it is often applied in newborns with respiratory failure, who cannot be successfully managed with conventional mechanical ventilation (CMV). The results of recent studies investigating the theoretically diminished baro- and volutrauma remain equivocal. Nonetheless there is evidence for a decreased secretion of inflammatory mediators [2] and a reduced amount of lung oedema [3] using high-frequency oscillatory ventilation (HFOV) with or without additional application of exogenous surfactant.

Inhaled nitric oxide (iNO) as a treatment for neonatal pulmonary hypertension has been in use for the past few years, both in premature infants and in term neonates [49]. It is worth noting that the first published application of iNO in a premature infant, and the subsequent improvement of oxygenation, occurred during HFOV [10]. Although still an experimental treatment, NO inhalation plays an important therapeutic role in severe hypoxaemia of the newborn due mainly to extrapulmonary shunting $[11,12]$.

Recently, a randomized, multicentre trial showed that the combination of iNO and HFOV was superior in term neonates, as compared to either treatment alone [13]. We report a similar experience in a full-term neonate, but also in a premature infant of 29 weeks of gestation.
Neonatal Intensive Care Unit, University Children's Hospital, Freiburg, Germany.

Correspondence: T. Hoehn

NICU

University Children's Hospital

Mathildenstr. 1

79106 Freiburg

Germany

Fax: 00497612704399

Keywords: Alveolar recruitment high-frequency ventilation

lung expansion

nitric oxide

oxygenation

Received: June 51997

Accepted after revision September 261997

\section{Case 1}

The term infant was delivered by caesarean section because of maternal hypertension. There was no maternal history of infection. The infant was male and had a birth weight of 3,810 $\mathrm{g}$ and Apgar 9,10,10 (1',5',10'); he became symptomatic at the age of $15 \mathrm{~min}$ with intercostal retractions and grunting. At that stage, capillary blood gases were: $\mathrm{pH} 7.23$, capillary carbon dioxide tension $\left(P \mathrm{c}, \mathrm{CO}_{2}\right)$ $8.0 \mathrm{kPa}(60 \mathrm{mmHg})$, capillary oxygen tension $\left(P \mathrm{c}, \mathrm{O}_{2}\right) 4.0$ $\mathrm{kPa}(30 \mathrm{mmHg})$ in combination with an increasing inspiratory oxygen fraction $\left(F \mathrm{I}, \mathrm{O}_{2}\right)$. At the age of $2 \mathrm{~h}$ the neonatal transport team was called, which arrived about 1 $\mathrm{h}$ later. The infant was intubated and ventilated because of persistent cyanosis, antibiotic treatment was started and he was transferred to our neonatal intensive care unit. Upon arrival, bovine surfactant $\left(100 \mathrm{mg} \cdot \mathrm{kg}^{-1}\right)$ was applied; in order to achieve adequate oxygenation, peak inspiratory pressures (PIPs) up to $4.6 \mathrm{kPa}$ were required (positive endexpiratory pressure (PEEP) $0.5 \mathrm{kPa}$, rate 70 breaths $\cdot \mathrm{min}^{-1}$, inspiratory time $0.35 \mathrm{~s}$, mean airway pressure (MAP) 1.8 $\left.\mathrm{kPa}, F \mathrm{I}, \mathrm{O}_{2} 1.0\right)$. After approximately $6 \mathrm{~h}$ a sudden deterioration of oxygenation and arterial blood pressure occurred, caused by a pneumopericard, which was relieved by drainage. During this event, profound hypoxia occurred for about $15 \mathrm{~min}$, the continuously recorded arterial oxygen saturation $\left(\mathrm{S}_{\mathrm{a}}, \mathrm{O}_{2}\right)$ (measured by pulsoximetry) was approximately $20 \%$. Following drainage of the pneumopericard 
and simultaneous bilateral pneumothoraces a gradual stabilization was achieved. Only then was right-to-left shunting via the ductus arteriosus and the foramen ovale was diagnosed by echocardiography and a trial of iNO was started. Since no improvement in arterial

oxygenation occurred (figs. 1a and 2a), iNO was stopped and the mode of ventilation was switched to HFV (Baby$\log 8000$; Draeger, Luebeck, Germany). Ventilator settings at that stage were: MAP $2.4 \mathrm{kPa}$, rate $8 \mathrm{~Hz}$, amplitude $100 \%, F \mathrm{I}, \mathrm{O}_{2} 1.0$. Again no increase in arterial oxygen tension $\left(\mathrm{Pa}, \mathrm{O}_{2}\right)$ was recorded, so a second trial of iNO was commenced, this time during HFV. Within a few minutes, oxygenation improved rapidly (figs. $1 b$ and $2 b$ ), the oxygenation index decreased from 114 to 4 over a period of 3 $\mathrm{h}$, and the alveolar-arterial pressure difference for oxygen $\left(P \mathrm{~A}-\mathrm{a}, \mathrm{O}_{2}\right)$ decreased from 652 to 203 . Right-to-left shunting was no longer present on echocardiography, the improved oxygenation was sustained and iNO was gradually weaned over a period of 4 days. The initial concentration of NO was 70 parts per million (ppm), which was rapidly weaned to levels below 20 ppm. Peak $\mathrm{NO}_{2}$ was recorded at $3.7 \mathrm{ppm}$ and methaemoglobin was measured at a maximum of $1.7 \%$. Continuous monitoring of iNO and $\mathrm{NO}_{2}$ were performed using an electrochemical device (Bieler and Lang, Achern, Germany). Cranial ultrasound revealed a left-sided middle cerebral artery infarction, which was compatible with the electroencephalogram (EEG) findings; clinically no neurological abnormalities were noted. The infant was extubated after 10 days of HFV; no supplemental oxygen was required thereafter. The diagnosis was persistent pulmonary hypertension of the newborn (PPHN) caused by profound hypoxaemia secondary to pneumopericard and bilateral pneumothoraces.

\section{Case 2}

The female premature infant, 29 weeks of gestation, had a birth weight of 1,060 g, Apgar 7,8,8 (1',3',5'). She suffered severe postnatal asphyxia at age 20 min following spontaneous vaginal delivery. Lung hypoplasia due to prematurely ruptured membranes with subsequent oligohydramnios was suspected prenatally on sonography. Ventilator settings at that stage were: PIP $3.0 \mathrm{kPa}$, PEEP 0.5 $\mathrm{kPa}$, rate 60 breaths $\cdot \mathrm{min}^{-1}$, inspiratory time $0.3 \mathrm{~s}$, MAP 1.1
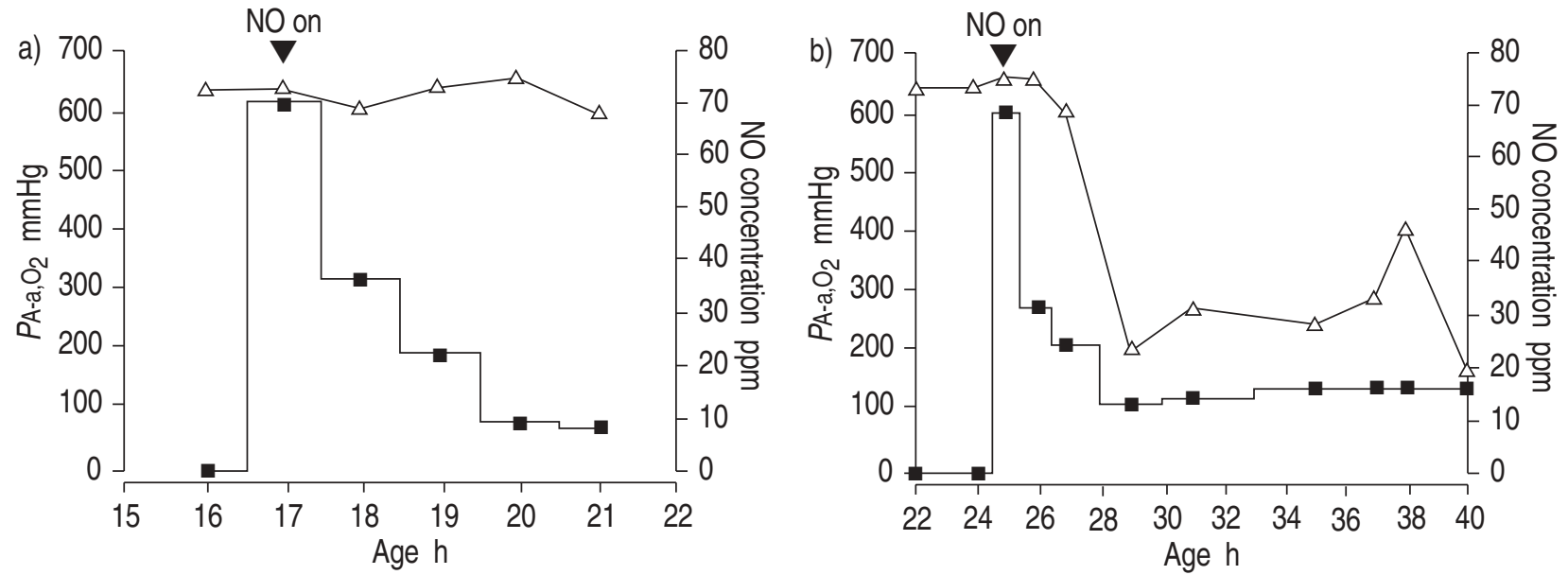

Fig. 1. - Alveolar-arterial pressure difference for oxygen $\left(P \mathrm{~A}-\mathrm{a}, \mathrm{O}_{2}\right)$ and NO concentration in a term infant (Case 1) during treatment with: a) conventional ventilation plus inhaled nitric oxide (iNO); and b) high frequency ventilation (HFV) plus iNO. $\mathbf{m}$ : NO; ý: PA-a, $\mathrm{O}_{2}$. ppm: parts per million. 1 $\mathrm{mmHg}=0.133 \mathrm{kPa}$.
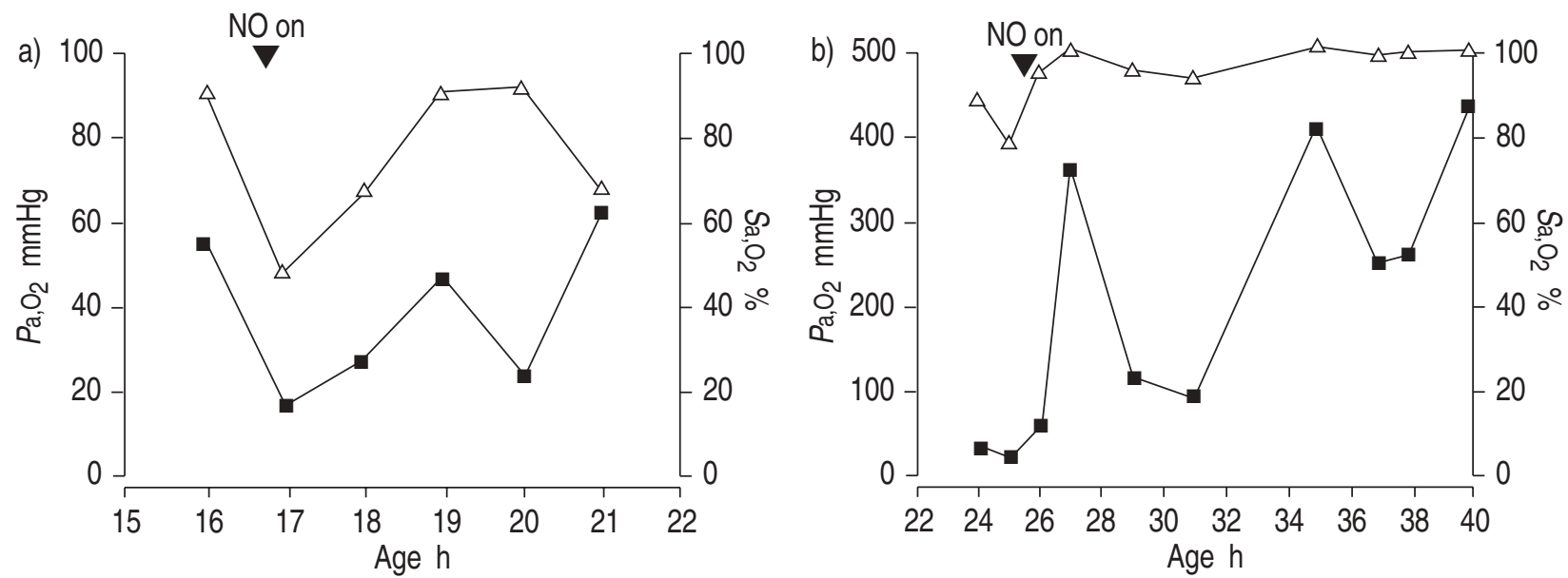

Fig. 2. - Arterial oxygen tension $\left(\mathrm{Pa}_{\mathrm{a}} \mathrm{O}_{2}\right)$ and arterial oxygen saturation $\left(\mathrm{Sa}, \mathrm{O}_{2}\right)$ in a term infant $($ Case 1$)$ during treatment with: a) conventional ventilation plus iNO; and b) HFV plus iNO. $\mathbf{~}: \mathrm{Pa}_{\mathrm{a}} \mathrm{O}_{2} ; \mathrm{y}: \mathrm{Sa}_{\mathrm{a}} \mathrm{O}_{2}$. For definitions see legend to figure $1.1 \mathrm{mmHg}=0.133 \mathrm{kPa}$. 
$\mathrm{kPa}$ and $F \mathrm{I}, \mathrm{O}_{2}$ 1.0. Echocardiography revealed right-to- left shunting via the ductus arteriosus and the foramen ovale and, in addition, tricuspid valve incompetence with a pulmonary arterial pressure gradient of $40 \mathrm{mmHg}$ was demonstrated. A subsequent trial of iNO did not lead to any improvement in terms of oxygenation, as monitored by $P \mathrm{a}, \mathrm{O}_{2}$ and $\mathrm{Sa}, \mathrm{O}_{2}$ (figs. $3 \mathrm{a}$ and $4 \mathrm{a}$ ). In order to treat persistent hypoxaemia, mechanical ventilation was switched to the high-frequency mode (Babylog 8000), which led only to a minor increase in $\mathrm{Sa}_{2} \mathrm{O}_{2}$ (settings: MAP $1.2 \mathrm{kPa}$, rate 11 $\mathrm{Hz}$, amplitude $100 \%, F \mathrm{I}, \mathrm{O}_{2} 1.0$ ). Following initia-tion of HFV a second trial of iNO was started. Within several minutes a pronounced improvement of oxygenation occurred (figs. 3b and 4b), which was sustained and permitted gradual weaning from the ventilator. The initial iNO dose was $70 \mathrm{ppm}$ and was then gradually reduced to a concentration below $10 \mathrm{ppm}, \mathrm{NO}_{2}$ and methaemoglobin were below $4.4 \mathrm{ppm}$ and $1.6 \%$, respectively. After only 1 h of iNO therapy $F \mathrm{I}_{1} \mathrm{O}_{2}$ was 0.21 , the infant was extubated after 5 days of $\mathrm{HFV}$ and did not require supplemental oxy-gen during spontaneous breathing. The cranial ultrasound showed a normal anatomy with no evidence of intra-cranial haemorrhage, this was also the case during further follow-up.

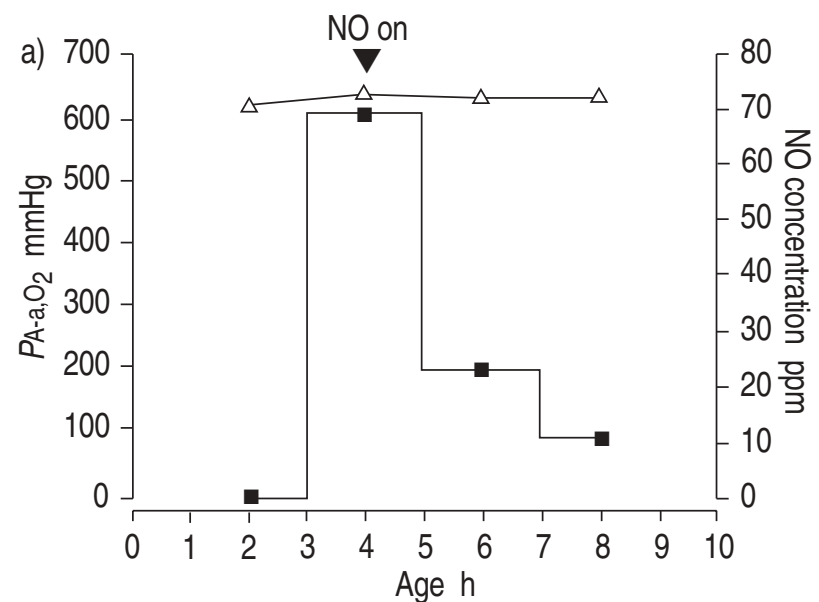

The diagnosis was persistent pulmonary hypertension of the newborn (PPHN) due to profound hypoxaemia following postnatal asphyxia and lung hypoplasia.

\section{Discussion}

In the two neonates with hypoxaemia described above (one premature infant of 29 weeks of gestation, one term infant) we found that combined treatment with HFV and iNO resulted in superior improvement in oxygenation when compared to the remaining three ventilatory regimens.

In order to evaluate the influence of the mode of ventilation on arterial oxygenation we chose a sequential approach, applying four different modalities: 1) conventional ventilation; 2) conventional ventilation plus iNO; 3) $\mathrm{HFV}$; and 4) HFV plus iNO.

Earlier studies comparing HFV and conventional ventilation without differentiating between high and low volume strategies failed to prove benefits from the use of HFV in terms of oxygenation [14, 15]. In contrast, recent studies have shown that HFV acutely improves oxygenation in preterm infants with respiratory failure [16-20]. This is in contrast to the present findings, in which there

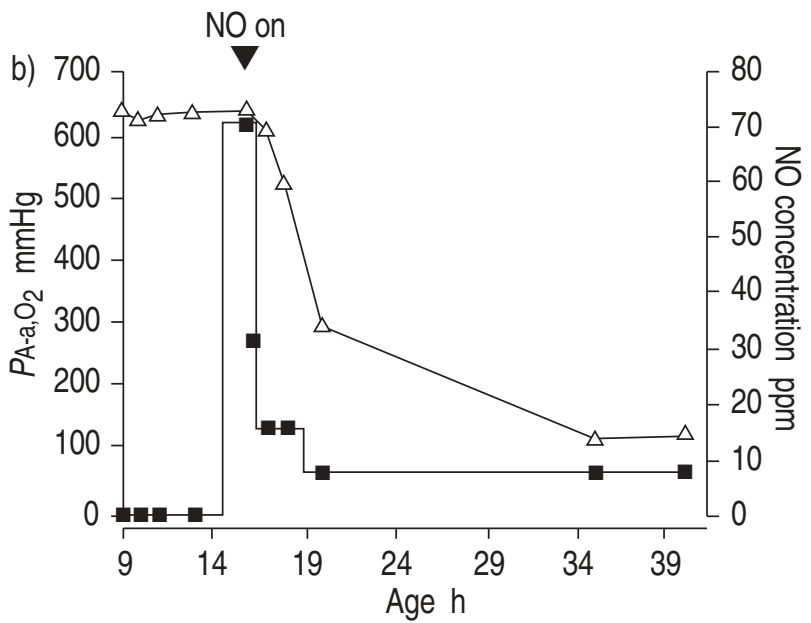

Fig. 3. - $\mathrm{Pa}_{\mathrm{a}} \mathrm{O}_{2}$ and $\mathrm{Sa}_{\mathrm{a}} \mathrm{O}_{2}$ in a preterm infant of 29 weeks of gestation (Case 2) during treatment with: a) conventional ventilation plus iNO; and b) $\mathrm{HFV}$

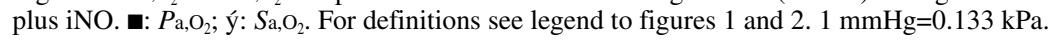
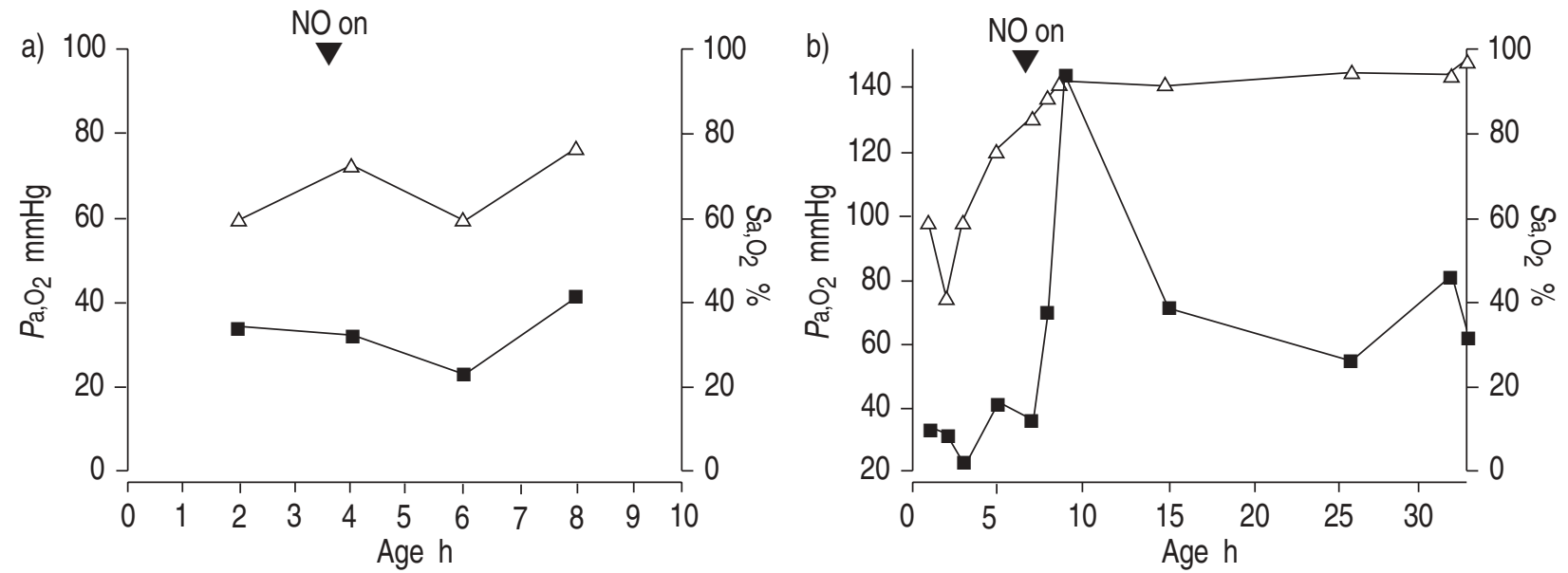

Fig. 4. - $P \mathrm{~A}-\mathrm{a}, \mathrm{O}_{2}$ and $\mathrm{NO}$ concentration in a premature infant of 29 weeks of gestation (Case 2) during treatment with: a) convention ventilation plus iNO and b) HFV plus iNO. $\mathbf{m}: \mathrm{NO} ; y$ : $P \mathrm{~A}-\mathrm{a}, \mathrm{O}_{2}$. For definitions see legend to figure $1.1 \mathrm{mmHg}=0.133 \mathrm{kPa}$. 
was no more than a marginal improvement in oxygenation following the initiation of HFV. It is noteworthy that this lack of improvement occurred despite the use of higher mean airway pressures during HFV. According to the clinical experience of a variety of investigators, following the change from conventional ventilation to HFV mean airway pressures $0.1-0.2 \mathrm{kPa}$ higher than those used with CMV are required [21]. This was the case in the premature infant (CMV: MAP 1.1 kPa; HFV: MAP 1.2 kPa), but not in the term infant (CMV: MAP $1.8 \mathrm{kPa}$; HFV: MAP $2.4 \mathrm{kPa}$ ). The increase in MAP was justified on clinical grounds in order to ensure adequate oxygenation. Although the concomitant alveolar recruitment did not lead to a decrease of oxygenation parameters, we do believe that this was the reason for a favourable response to the second trial of iNO. The high-frequency ventilator used (Babylog 8000) is a flow interrupting device. The Baby$\log$ requires high inspiratory flow rates (up to $30 \mathrm{~L} \cdot \mathrm{min}^{-1}$ ) and oscillations are created by an expiratory valve.

Inhaled nitric oxide has been shown to be a very potent pulmonary vasodilator in the newborn infant. According to several publications this is not only the case in term infants [4, 5, 22], but also in premature neonates [7-9]. Although it still has to be regarded as an experimental treatment and a variety of potential side-effects have to be looked at, iNO has emerged as a very promising therapeutic approach in PPHN. The probability of a positive clinical response to iNO in terms of improved oxygenation depends basically upon the underlying disease [13]. In the past the attempt has been made to define NO-responders and nonresponders according to their degree of improvement of oxygenation parameters. This remains at least controversial since, according to several authors, patients may only respond favourably in the course of several attempts of iNO, which is in line with our own experience. Response or nonresponse might be directly related to the degree of lung expansion [23], which can be inconsistent during the course of the underlying disease. The clinical response to iNO might also depend on the choice of the ventilatory strategy, since the regional distribution of NO changes with different modes of ventilation (CMV/ HFOV/high-frequency jet ventilation) [24].

Side-effects of NO seen in in vitro investigations include an inhibition of platelet aggregation and adhesion [25]. Although, theoretically of serious concern, particularly in preterm infants, impairment of platelet function does not appear to occur clinically during iNO therapy. This is consistent with the findings of the recently published North American multicentre studies [11, 12], including infants from 34 weeks onward as well as a series of premature infants treated with iNO [8-10]. The fact that gestational age and weight ruled out proceeding to extracorporeal membrane oxygenation (ECMO) in the 29 weeks infant, and the profound hypoxaemia, led to the decision to apply iNO, despite the theoretically increased risk of intraventricular haemorrhage.

The dosage regimen of iNO implied the initial use of concentrations in the upper range of those used clinically. This approach is derived from the three North American randomized trials of inhaled nitric oxide using concentrations up to $80 \mathrm{ppm}$ (Boston Massachusetts General Hospital [11], Boston Children's Hospital, Ohmeda (both unpublished)). Subsequently we aimed at a rapid reduction of iNO concentrations (figs. 1 and 3). Meanwhile, there is evidence that a favourable response to iNO can be achieved with starting doses of $20 \mathrm{ppm}$ or less [5, 26].

Recently Kinsella et al. [27] found an improvement in oxygenation in an animal model (the newborn lamb) using the combination of iNO and HFOV as compared to iNO and conventional ventilation. Subsequently they demonstrated that the combination of iNO and HFOV was superior to either treatment alone in human neonates with severe PPHN, who were candidates for extracorporeal membrane oxygenation (ECMO) [13]. An animal model using dogs with oleic acid-induced lung injury showed that a recruitment of gas exchange units with continuous positive airway pressure (CPAP) was necessary in order to produce a beneficial effect of iNO on the ventilationperfusion distribution and oxygenation [28, 29]. In patients with adult respiratory distress syndrome (ARDS), the factors determining NO-induced improvement in arterial oxygenation and pulmonary vascular effects have been shown to be PEEP-induced alveolar recruitment and the baseline level of pulmonary vascular resistance [30]. According to these findings, the beneficial effect of combining iNO and HFV might be solely related to the increased degree of alveolar recruitment during HFV. A more homogenous lung expansion during HFV would appear to overcome the problem of varying opening pressures required for different compartments of the lung. This not only explains an earlier reduction of $F \mathrm{I}, \mathrm{O}_{2}$ in the HFOV group in the latest multicentre HFOV trial [31], but also leads to the expectation of a more uniform distribution and resorption of iNO.

In the two cases described above we found a clear benefit, in terms of improved oxygenation, from the combination of high-frequency ventilation and inhaled nitric oxide, which could not be achieved by conventional ventilation and inhaled nitric oxide. This was not only the case in the term infant, but also in a premature infant of 29 weeks of gestation. We conclude that in order to reach the maximum effect of inhaled nitric oxide, adequate lung expansion is required. This appears to be more readily achieved by the use of HFV. A randomized, controlled trial evaluating the effect of the mode of ventilation on the efficacy of inhaled nitric oxide is necessary before clinical conclusions can be drawn.

\section{References}

1. Haase CM, Kennaugh JM, Clarke DR. Adaptation of an ECMO team in the era of successful alternative therapies for neonatal pulmonary failure. J Ped Surg 1995; 30: 674-678

2. Imai $\mathrm{Y}$, Kawano $\mathrm{T}$, Miyasaka $\mathrm{K}$, Takata M, Imai $\mathrm{T}$, Okuyama K. Inflammatory chemical mediators during conventional ventilation and during high frequency oscillatory ventilation. Am J Respir Crit Care Med 1994; 150 : 1550-1554.

3. Jackson JC, Truog WE, Standaert TA, et al. Reduction in lung injury after combined surfactant and high-frequency ventilation. Am J Respir Crit Care Med 1994; 150: 534-539.

4. Roberts JD, Polaner DM, Lang P, Zapol WM. Inhaled nitric oxide in persistent pulmonary hypertension of the newborn. Lancet 1992; 340: 818-819.

5. Kinsella JP, Neish SR, Shaffer E, Abman SH. Low-dose 
inhalational nitric oxide in persistent pulmonary hypertension of the newborn. Lancet 1992; 340: 819-820.

6. Milner AD, Aiton N. Nitric oxide inhalation. Pediatr Pulmonol 1995; 11: 100-101.

7. Peliowski A, Finer NN, Etches PC, Tierney AJ, Ryan $\mathrm{CA}$. Inhaled nitric oxide for premature infants after prolonged rupture of the membranes. J Pediatr 1995; 126: $450-453$.

8. Ahluwalia JS, Kelsall AW, Raine J, Rennie JM, Mahmood M, Oduro A. Safety of inhaled nitric oxide in premature neonates. Acta Paediatrica 1994; 83: 347-348.

9. Hoehn T, Krause M, Wildberg A, Pringsheim W, Leititis JU. Umkehr eines Rechts-Links-Shunts und dauerhafte Verbesserung der Oxygenierung durch Inhalation von Stickstoffmonoxyd (NO) bei einem Frühgeborenen mit Lungenhypoplasie und Asphyxie. Z Geburtsh Neonatol 1997; 201: 105-107.

10. Abman SH, Kinsella JP, Schaffer MS, Wilkening RB. Inhaled nitric oxide in the management of a premature newborn with severe respiratory distress and pulmonary hypertension. Pediatrics 1993; 92: 606-609.

11. Roberts JD Jr, Fineman JR, Morn FC 3rd, et al. Inhaled nitric oxide and persistent pulmonary hypertension of the newborn. N Engl J Med 1997; 336: 605-610.

12. The Neonatal Inhaled Nitric Oxide Study Group. Inhaled nitric oxide in full-term and nearly full-term infants with hypoxic respiratory failure. N Engl J Med 1997; 336: 597604.

13. Kinsella JP, Truog WE, Walsh WF, et al. Randomized, multicenter trial of inhaled nitric oxide and high-frequency oscillatory ventilation in severe persistent pulmonary hypertension of the newborn (PPHN). Pediatr Res 1996; 39(4): 222A.

14. HIFI Study Group. High-frequency oscillatory ventilation in the treatment of respiratory failure in preterm infants. $N$ Engl J Med 1989; 320: 88-93.

15. Froese AB, Butler PO, Fletcher WA, Byford LJ. High-frequency oscillatory ventilation in premature infants with res-piratory failure: a preliminary report. Anesth Analg 1987; 66: 814-824.

16. Clark RH, Gerstmann DR, Null DM, deLemos RA. Prospective randomized comparison of high-frequency oscillatory and conventional ventilation in respiratory distress syndrome. Pediatrics 1992; 89: 5-12.

17. Bhuta T, Henderson-Smart DJ. Meta-analysis of elect- ive high-frequency oscillatory ventilation in preterm in-fants with pulmonary dysfunction. Pediatr Res 1996; 39(4): 326A.

18. HIFO Study Group. Randomized study of high-frequency oscillatory ventilation in infants with severe respiratory distress syndrome. J Pediatr 1993; 122: 609-619.

19. Ogawa Y, Miyasaka K, Kawano T, et al. A multicenter randomized trial of high-frequency oscillatory ventilation as compared with conventional mechanical ventilation in preterm infants with respiratory failure. Early Hum Dev 1993; 32: 1-10.

20. Siles Quesada C, Puyol Buil P, Omenaca Teres F, et al. High-frequency ventilation in the newborn. Study of 27 cases. An Esp Pediatr 1992; 37: 361-365.

21. Truog WE. High-frequency oscillatory ventilation. In: Spitzer AR, ed. Intensive Care of the Fetus and Neonate. St Louis, Mosby, 1996; pp. 584-593.

22. Bührer C, Merker G, Falke K, Versmold H, Obladen M. Dose-response to inhaled nitric oxide in acute hypoxemic respiratory failure of newborn infants: a preliminary report. Pediatr Pulmonol 1995; 19: 291-298.

23. Carter JM, Gerstmann DR, Clark RH, Snyder G, Cornish JD, Null DM Jr. High-frequency oscillatory ventilation and extracorporeal membrane oxygenation for the treatment of neonatal respiratory failure. Pediatrics 1990; 85: 159-164.

24. Taulane J, Robinson NB, Ginda M, Shaffer TH, Billmire D, Wolfson MR. Regional distribution of nitric oxide (NO) and nitric dioxide $\left(\mathrm{NO}_{2}\right)$ during inhalational therapy: effect of ventilation strategy. Pediatr Res 1996; 39(4): 391A.

25. Änggard E. Nitric oxide: mediator, murderer, and medicine (Review). Lancet 1994; 343: 1199-1206.

26. Kinsella JP, Neish SR, Ivy DD, Shaffer E, Abman SH. Clinical responses to prolonged treatment of persistent pulmonary hypertension of the newborn with low doses of inhaled nitric oxide. J Ped 1993; 123: 103-108.

27. Kinsella JP, Parker TA, Galan H, Ivy DD, Abman SH. High-frequency oscillatory ventilation augments the response to inhaled nitric oxide in severe experimental hyaline membrane disease. Pediatr Res 1996; 39(4): 336A.

28. Putensen C, Räsänen J, Lopez FA, Downs JB. Continuous positive airway pressure modulates effect of inhaled nitric oxide on the ventilation-perfusion distribution in canine lung injury. Chest 1994; 106: 1563-1569.

29. Putensen C, Räsänen J, Downs JB. Effect of endogenous and inhaled nitric oxide on the ventilation-perfusion relationships in oleic-acid lung injury. Am J Respir Crit Care Med 1994; 150: 330-336.

30. Puybasset L, Rouby J-J, Mourgeon E, et al. Factors influencing cardiopulmonary effects of inhaled nitric oxide in acute respiratory failure. Am J Respir Crit Care Med 1995; 152: 318-328.

31. Gerstmann DR, Minton SD, Stoddard RA, et al. The provo multicenter early high-frequency oscillatory ventilation trial: improved pulmonary and clinical outcome in respiratory distress syndrome. Pediatrics 1996; 98: 1044-1057. 